\title{
Exploring the Effectiveness of STEAM Integrated Approach via Scratch on Computational Thinking
}

\author{
Wee-Ling Tan ${ }^{1}$, Mohd Ali Samsudin ${ }^{1 *}$, Mohd Erfy Ismail ${ }^{2}$, Nur Jahan Ahmad ${ }^{1}$, Corrienna Abdul Talib ${ }^{3}$ \\ 1 Universiti Sains Malaysia, MALAYSIA \\ 2 Universiti Tun Hussein Onn Malaysia, MALAYSIA \\ ${ }^{3}$ Universiti Teknologi Malaysia, MALAYSIA
}

Received 23 July 2021 - Accepted 15 November 2021

\begin{abstract}
This study examined the effectiveness of STEAM (Science, Technology, Engineering, Art, Mathematics) integrated approach via Scratch on five subconstructs of computational thinking (CT) among 29 male and 30 female students. A quasi-experimental design was employed in the research. The participants demonstrated the application of CT in designing games via Scratch during the intervention. The Computational Thinking Survey (CTS) was administered pre-CT and post- $C T$ tests in measuring the five subconstructs of $C T$. Repeated multivariate analysis of variance (MANOVA) results showed that the intervention positively affected male and female students' comprehension concerning the five subconstructs of $C T$. The results were strengthened by the repeated measure of analysis of variance (ANOVA) with posthoc comparisons, indicating all five subconstructs of CT increased significantly $(p<.05)$. Indirectly, this research introduced a new teaching methodology for students' $\mathrm{CT}$ level in the current electronic and technology-advanced era and increased concept manipulation capacity among male and female students.
\end{abstract}

Keywords: computational thinking, constructionism theory, five subconstructs of computational thinking, Scratch, STEAM integrated approach

\section{INTRODUCTION}

Science, Technology, Engineering, and Mathematics (STEM) education has gained popularity among science education with the interdisciplinary and transdisciplinary learning approach (Liliawati et al., 2018). STEM education emphasizes enhancing science and mathematics as an integrated discipline and focuses on technology (Liliawati et al., 2018) in solving the problem. Nevertheless, many debates and suggestions on art integration into STEM have been voiced to maximize the STEM impacts in the science educational reformation (Bertrand \& Namukasa, 2020). The educators' dissatisfaction with the students' poor academic achievement and failure to relate the knowledge learned in solving the daily life problems under STEM education stimulate the art integration into STEM (Bertrand \& Namukasa, 2020).
This prompts the popping out of researches on Science, Technology, Engineering, Art and Mathematics (STEAM) education in switching educational paradigms. The art integration in science learning is by communicating the science idea in images, texts, and other visual information (Bertrand \& Namukasa, 2020), especially the abstract concepts. Art (A) is integrated into STEM, and it enhances students' science learning through the STEM concepts visualization in the viewpoint of the art (Belbase et al., 2021; Jolly, 2014) with art experience.

Through the art experience, students undergo aesthetic judgment, attitude, aesthetic understanding, aesthetic emotion, and aesthetic value (Hekkert \& Leder, 2007). All the art is aesthetics (Dewey, 1996). The aesthetics value of art is the determining factor in scientific knowledge progress, and revolution (McAllister, 1996) as science and art share the common aesthetic characteristic and aesthetic theory (Root-

(c) 2021 by the authors; licensee Modestum. This article is an open access article distributed under the terms and conditions of the Creative Commons Attribution License (http://creativecommons.org/licenses/by/4.0/). 


\section{Contribution to the literature}

- The current research also contributes to the body of literature by presenting a new approach based on the STEAM integrated approach in science learning.

- This research also confirmed that the STEAM integrated approach via Scratch could improve students' CT in science learning.

- Moreover, the findings contribute to the understanding that male and female students have the same achievement and performance in CT with the STEAM integrated approach.

Bernstein, 1997). In this context, aesthetics does not only serve the purpose on the artistic creation but also the process of artistic creation and experience. This pleasing aesthetics experience includes meaning satisfaction, excitement, self-satisfaction, interesting and even ugly values pay the contribution to the aesthetic experience (Süzen, 2020). Therefore, the field of aesthetics value of art in STEAM research is focused not only on the art but also on how students communicate on artwork and perceive the artwork during the STEAM integrated approach intervention.

Hence, there is no controversy between STEAM learning and STEM learning but instead enhancing and enlarging the STEM education scope. The STEAM authorises teachers to conduct project-based learning across every five disciplines and encourage an engaging and interactive aesthetics learning environment (Liliawati et al., 2018). The design is abstract, but through the art, the learning process is visualised with seeing and feeling in the socialisation process, to find solutions to the problems faced. Aesthetics of art contributes to the personal physical, mental and social development (Süzen, 2020). This creates robust solutions and products by designing meaningful interdisciplinary aesthetics projects that close the gap between disciplines. In design, creating pleasing aesthetics in a product leads to better usability and user experience, and aesthetic value (Hekkert \& Leder, 2007). Hence, the aesthetic experience plays a vital role in scientists and in doing science and to well-functioning science in class. So, in this research, the electricity concepts' abstract concepts can be contextualised and visualised with the A (art) in the STEAM, which incorporates multiple disciplines simultaneously. The role of aesthetics value of art is essential as a tool for scientific inquiry and abstract reasoning in the context of science education (Hammer, 2014) is undeniable.

Even though STEM education incorporates multiple disciplines to promote learning experiences, STEM skills seem insufficient in nurturing other problem-solving skills that enable students to explore, experiment, study, discover and practice innovative problem-solving skills (Belbase et al., 2021). Under the STEAM framework, students are exposed to the subject matter knowledge and skills in solving-problem by knowing the interactive method to learn, think critically, creativity, ask questions, discover, and create possible solutions
(Belbase et al., 2021). In short, the principal concept of STEAM education is to promote aesthetic experience arts-based learning to discover new skills and approaches in cultivating creative and collaborative problem-solving skills (Belbase et al., 2021). Hence, this research's primary purpose was to understand better the aesthetics value of art in the STEAM integrated approach and the potential of art in STEAM in enhancing electricity concepts comprehension level among students by nurturing the CT skills. This research has implications for designing the practical teachinglearning tasks in STEAM programs and how students solve learning difficulties with CT by implemented the STEAM integrated approach method with applied Science, Technology, Engineering, Art, and Mathematics element.

In this research, the STEAM integrated approach via Scratch comparatively taught both gender of students and beyond discipline character-building five subconstruct of CT skills. The five subconstruct CT skills taught included: algorithmic thinking, cooperativity, creativity, critical thinking, and problem-solving skill. The researcher uses the electricity games design activities to identify whether there is a change in the ability to apply the five subconstruct CT skills in each learning process before and after learning. The electricity games designed provided a scientific and art experience for students to carry out a series of algorithmic thinking, cooperativity, creativity, critical thinking, and problemsolving skills to produce innovative games in learning. This STEAM integrated approach learning environment provides multiple entry points, multiple ways to approach a problem, and multiple aesthetics representations in the game were designing on electricity concepts activities with the CT. Meanwhile, STEAM learning emphasizes the involvement of students in constructing their own aesthetics science learning. Spyropoulou et al. (2020) acknowledged that STEAM learning makes students appreciate the implication of art and science in many forms of critical thinking skills, creativity, and imagination when they try to understand real problems during a games development. STEAM learning activities can be achieved by observation and experimentation through games development based on the electricity concept.

The theme of electricity was chosen because it combined some essential competencies into an exciting 
theme that can make time more effective and can facilitate students in understanding material or concepts. In addition, electricity is an essential component of our lives. Therefore, with the theme of electricity, students can understand the meaning of current, voltage, and resistance, the different types of electric circuits, and the calculation of the current, voltage, and resistance in a different circuit in an innovative way STEAM integrated approach. By studying the theme of electricity, students can realise the concept of science that exists in the everyday phenomenon, making it easier for students to learn with the art integration.

In contrast to other research on STEAM, this research identifies the CT skills and the competency in applying CT skills across the STEAM disciplines. Also, the research stresses the enduring aesthetics value of the art element in STEAM integrated approach engagement with different genders of students, which has the potential to impact change in learning electricity concepts and solving problems with art and science such as in STEAM. However, empirical research on STEAM education is in its infancy, and little research has compared the capability of male and female students to develop CT skills through art integration in STEAM education. The research compares the aesthetic experience through games designed by male and female students and focuses mainly on the CT application across the STEAM disciplines in designing the game with an electricity theme.

\section{Research Problem}

CT is fundamental in analytical thinking (Bati, 2018) when focusing on solving problems, designing systems, and understanding human behaviour (Curzon et al., 2009; Wing, 2006). However, the application of CT is often confined and applied to activities in programming design and computer science (Hsu et al., 2018). Even though programming is commonly used as important activities in developing students' CT, some researchers have pointed out that students focused more in learning programming language than problem solving with CT (Buitrago Flórez et al., 2017; Li et al., 2020). In this case, Qin (2009) proved that CT provides a vital skill set in modern sciences (Qin, 2009). In fact, as Denning (2009, 2017) pointed out, CT has long been used in many professional fields likes physics and biology besides computer science. For example, problem solving and model building in biology research (Brodland, 2015) and climate management (Garner et al., 2016).

Previous research finding proved that abstract concepts in science delay the students' improvement in learning because no proper and correct methods or guidance were available for students to deal wtih the theoretical concepts in education and solve the difficult questions (Anderman et al., 2012). Moreover, students find utilising human creativity and critical thinking challenging to enhance social problem-solving
(Anderman et al., 2012). On the other hand, Gal-Ezer and Zur (2004) acknowledged that nurturing CT is not easy since CT was not included in primary and secondary school curricula. CT is only used in teaching data structures and university programming courses.

Besides that, many teachers faced the difficulties in developing and designing particular educational activities for teaching CT to students (Hsu et al. 2018; Li et al., 2020) due to the reason the complexity of the multiple nature of $\mathrm{CT}$, but also to the wide range of different interventions and educational programs (Shute et al., 2017). Besides that, integrating CT in interdisciplinary education of STEAM is a new topic ( $\mathrm{Li}$ et al., 2020; Li, 2018). Some researchers proposed alternative methods to develop problem-solving with CT such as, "systematic CT" (Michaelson, 2018) and "creative computational problem solving" (Chevalier et al., 2020). However, the significance of CT in STEAM fields did not automatically translate into school instruction (Li et al., 2020).

STEAM education has gained recognition as an educational movement in different parts of the world (Liao, 2016). Although STEAM education has been increasingly emphasised in schools, most STEAM studies focused on computer science and computing programming. Problem-solving skills among students are challenging to be developed when learning science in STEAM studies. Most STEAM education studies utilise the model as the context-based learning approach (Metz, 2007; Papanikolaou, 2010; Yakman, 2008) and the importance of the STEAM education system (Conde et al., 2019). Only a smaller number of STEAM researchers developed skills in solving science learning lessons (Metz, 2007). Integrating the STEAM approach in the present educational background is complicated (Conde et al., 2019). Concentrating on a single subject and combining all the five disciplines into one item without losing the initial quality and learning objectives is challenging (Conde et al., 2019). The unsuitable teaching method caused confusion and misconception for the scientific concepts and consequently deteriorated the enthusiasm in learning (Dolgopolovas \& Dagiené, 2021).

Similarly, integrating science and art or engineering into other subjects is tough as there is no similarity in learning objectives (Conde et al., 2019). Experts in the field might support the difficulty of integrating, but a new problem might be created as only qualified teachers can teach painting and music, while engineering experts are not employed as teachers in schools (Conde et al., 2019). The more critical part is identifying the most critical contents to be followed and steps to be pursued by science educators to adopt a practical STEAM approach. Besides that, gender effect on the application of a practical STEAM approach also being one of the consideration of determining the effectiveness of STEAM integrated approach. Meinck and Brese (2019) as well as (Gatan et al., 2021) claimed that gender effect do 
exist due to the education policy and teaching method implication. It is supported by Cimpian et al. (2020) by acknowledging that gender inequality is getting obvious as the workforce is becoming male dominated. The alarming gender disparity have been identified in the 2015 United Nations General Assembly and recognizes that females' important role in th society (United Nations, 2015). UNESCO (2017) acknowledged that females played the vital contribution as the problem solver on the nowadays problems besides males. Hence, in solving the gender disparity, Iglesias et al. (2018) claimed that STEAM influenced gender equality in STEAM classrooms. Metz (2007) also agreed with the potential of STEAM education in reducing the gender gap.

Moreover, there was hardly any research of the aesthetic sides of science in science education, and often aesthetics is pictured in other subjects rather than science (Wickman, 2006). Only a small number of research based on the aesthetic experience that comprises the aesthetic objectively, as a universal phenomenon, was carried out (Van Maanen, 2009). Hence, it is undeniable that the aesthetic sides of science have been greatly neglected in science educational studies. Most students have the concept of science as the reproduction of history or a solipsistic individual construction (Wickman, 2006). This caused the knowledge regarding aesthetics' contribution to science education has not advanced much (Hammer, 2014). Hence, the role of these aesthetic experiences in doing science in class through the art element in the STEAM integrated approach was studied here to order to find out that the aesthetic experiences are not only simply a motivational driving mechanism nor making students evaluate science by making it more fun. This study determined the function of aesthetics in science in cognitive relevance for understanding science or judging what counts and does not count in science. That was the reason this research adopted a practical STEAM integrated approach by employing Scratch to enhance the CT level and raising awareness of persisting inequity gender issues. Based on these concerns, this research aimed to address the gap mentioned above in the research.

\section{THEORETICAL FRAMEWORK}

A STEAM integrated approach using Scratch was applied in this research, encompassing new integrating teaching and learning science approaches to enhance $\mathrm{CT}^{\prime}$ 's five subconstructs, namely algorithmic thinking, cooperation, creativity, critical thinking, and problemsolving.

\section{It is STEAM and Not STEM}

Science, Technology, Engineering, and Mathematics (STEM) education gained popularity in the United States and Europe in the 21st century (Bati et al., 2018), while
STEAM education was widely promoted in South Korea (Kang, 2019; Park et al., 2016). Although the STEAM education movement was implemented concurrently with STEM (Kang, 2019), the educational achievement results differed. Under the STEAM education, South Korean students had shown significantly outstanding successes in international student evaluation, likes the Programme for International Student Assessment (PISA) and the Trends in International Mathematics and Science Study (TIMSS) (Park et al., 2016). STEAM is implicated as an advanced version of STEM and as the knowledge and skills supplier for context-specific projects and problem-based education approaches (Dolgopolovas \& Dagienè, 2021).

Both STEM and STEAM education encompasses the disciplines of science, technology, engineering, and mathematics in an integrated manner (Tunc \& Bagceci, 2021) while educating students to design solutions in solving real-world problems. In comparison, STEM and STEAM education might overlap on specific methodology; however, STEAM introduces the concept of artistic discipline (Kang, 2019), fostering creativity, global awareness, design, and literature (Baek et al., 2012). Hence, while STEM education is more technology focus, and artistic principles bind STEAM education with a technology-based curriculum. To make that happen, STEAM infused artistic disciplines into STEM instruction. Arts modalities are used to interpret, present, and share STEM work, and the arts are a helpful assessment tool for STEM learning (Kelly \& Knowlws, 2016).

Artistic values are rarely focused in STEM education, even when preparing the scientific-artistic collaboration syllabus (Kang, 2019). In the STEM program, it is rarely seen that students could make connections between science and artistic design principal and even in the idea of applied science (Segarra et al., 2018). The additional artistic component into STEM education (Kang, 2019) meets the challenges of preparing a quality literate, creative, and well-rounded workforce while fulfilling a highly technology-based society (Baek et al., 2012; Bahrum et al., 2017). So, the artistic component under STEAM education should be seen as a mutual component rather than teaching aids. With art integration in STEM, students gain broader access to scientific concept learning, build technical skills hidden in the curriculum, and enhance students' mastery of design and cross-disciplinary collaboration (Segarra et al., 2018). Successful integration of art into STEM was displayed by several meta-analyses as students' experiences in STEAM education display improved cognitive and affective learning (Kang, 2019). Nevertheless, the effect is more substantial in affective domains.

From the aspect of the application, STEM and STEAM education have also seen the differences. STEAM education strengthens STEM education 
(Bahrum et al., 2017; Dolgopolovas \& Dagienė, 2021), whereby the identified differences are the extra characteristics found in STEAM education and not in STEM. Firstly, STEM education demonstrates the understanding of science and mathematics standards being taught in the classroom, whereas STEAM education uses the arts to demonstrate understanding of science and mathematics standards being taught in the classroom (Moore et al., 2014). Secondly, in explaining the characteristic of STEM, STEM uses the knowledge of Mathematics and science knowledge to create technologies using an engineering approach, whereas STEAM education is interpreted through engineering and the arts, all based on Mathematical elements (Kelly \& Knowlws, 2016). In analytical thinking, Land (2013), and Tunc and Bagceci (2021) claimed that the traditional STEM approach is developing analytical thinking skills, but both analytical and creative thinking skills come to the forepart in STEAM education approach. Students analyse and diagnose science and mathematics questions and use algorithmic thinking to narrate the problem briefly. According to Weintrop et al. (2016), STEAM classrooms provide computational tools and practices to students and prepare them with a more realistic view of these fields.

Both STEM and STEAM education reflects real-life application and problem-solving skills. Nevertheless, the literature review by Papanikolaou (2010), and Yamak et al. (2014) shows that most STEM education practices are focused on technology development in the contextbased learning approach and confined to software and robot construction, rather than solving real-life problems. Yet, STEAM allows developing STEM skills to frame the STEM projects in a more practical, real-world setting so that students can develop STEM skills and be applicable and integrated with the need of the natural world simultaneously (Brophy et al., 2008). Regardless of STEM embraces the 4C (creativity, collaboration, critical thinking, and communication), analysis, teamwork, and STEAM embrace the same component as STEM, but all are deeply rooted in the arts. Art introduces a new level of creativity, new ways to innovate and create, communicate complex information, sparking students' imagination, demonstrate new and exciting ways of thinking and problem-solving.

STEAM advocates argue that STEAM exploring where art naturally fits into the STEM subjects in STEAM education (Jolly, 2014; Kelly \& Knowlws, 2016; Moore et al., 2014; Oner et al., 2016). Adding some STEAM into STEM by applying design and computer graphics to projects or using the performing art to communicate a STEM project provides the tools to various learning styles. (Jolly, 2014; Kelly \& Knowlws, 2016; Moore et al., 2014; Oner et al., 2016). Hence, adding art to STEM does not take anything away from education. STEAM is applying creative thinking to STEM projects, enhancing students' imagination and creativity through arts.
STEAM education helps to improve, enhance and retain the skills and facts learned (Bahrum et al., 2017).

Conversely, some STEM advocates argue that art integration dilutes the STEM lesson as time on the core four subjects are minor (Kelly \& Knowlws, 2016; Moore et al., 2014). The STEM advocates also argue that enough creative thinking in Science and Engineering. So, it does not need to add another creative aspect to create the tomorrow thinker. In summary, STEAM provides a primary method for non-scientist citizens to engage with scientific ideas, questions, and narratives. Thus, they increase scientific literacy, awareness, potential action and have a more positive perception of STEAM-worthy goals for the scientific community. Therefore, the STEAM integrated approach was applied rather than STEM in this research.

\section{Aesthetics Value in Art}

Aesthetics is the branch of philosophy related to a sensory value (Süzen, 2020). Aesthetics means beauty or the beauty of the subject. In other words, aesthetics can be explained with sensory information directed towards beauty. In daily lives, aesthetics' is used to describe the sensitivity and style of a work of art (Süzen, 2020). The significance of sensory information and sensory perception through art has been revealed in the science or teaching of the beautiful and pleasing experience. Thus, those aesthetics researches were focused not on the art but the process of art creation (Süzen, 2020). Pleasure is an essential aesthetic experience to explore the understanding and solution underlying the phenomenon (Süzen, 2020). Aesthetic minds enable students to think, identify, define and explain concepts through a simple aesthetic idea across disciplines (Süzen, 2020) which contributes to forming profound perceptions and pleasant experiences in science learning, especially the abstract concepts. Hence, the contribution of the interaction of different disciplines in STEAM to students' artistic activities and art views was ensured in this research via the achievement in electricity concept and CT.

\section{Computational Thinking}

CT provides a better solution in academic or real-life situations (Park et al., 2015). Reality, there are lots of definitions on CT by the researcher (Bati et al., 2018; Curzon et al., 2009; Korkmaz et al., 2017; Park et al., 2015). Among all the definitions, CT is defined as the fundamental to compare and analyze several algorithms and solve a problem creatively with critical thinking (Gal-Ezer \& Zur, 2004). The CT combines logical, arithmetical, efficient, scientific, and innovative thinking and other thinking qualities, such as creativity and intuition (Curzon et al., 2009) in solving problems. The International Society for Technology in Education (ISTE) (2015) asserted that creativity, algorithmic thinking, 
critical thinking, problem-solving, communication, and cooperation as the workable solution to the students' problems were found under CT. Besides that, Henderson et al. (2007) also added that CT represented reasoning, the way people solve problems, both as humans and a computer, rather than thinking like a computer (Bati et al., 2018). CT can be utilized in generalizing and transferring the problem-solving process to a wide variety of problems in other disciplines or subjects (Curzon, 2015; Qin, 2009) besides computer science and programming.

So, among all the definitions found in defining the problems solving skills under the CT and the subconstructs CT-related skills (Korkmaz et al., 2017; Park et al., 2015), Korkmaz et al. (2017) had identified five subconstructs of CT, namely algorithmic thinking, cooperativity, creativity, critical thinking, and problemsolving. Even Doleck et al. (2017) also supported that CT can be best understood as an umbrella for algorithmic thinking, collaboration, creativity, critical thinking, and problem-solving. Therefore, the STEAM integrated approach via Scratch was used to enhance problemsolving skills with CT in this research, and yet it is vital in educating new generations of students in the twentyfirst century. Indirectly, the high capability to solve problems attributes a high locus of control personality in students' lives, whereby students have high confidence in handling and solving power (Ergün \& Külekci, 2019; Gatan et al., 2021).

\section{STEAM Integrated Approach into Science Learning}

The STEAM integrated approach integrates as a transdisciplinary epistemology. The STEAM disciplines via the aesthetics activities via Scratch were used in this research to enhance the five CT subconstructs identified by Korkmaz et al. (2017), namely algorithmic thinking, cooperativity, creativity, critical thinking, and problemsolving skills among students. A transdisciplinary potential in STEAM integrated approach allows the five disciplines to be taught based on one topic with spontaneous cross-curricular elements to be examined (Yakman, 2008). Students apply knowledge and practices across five different disciplines in STEAM (Kelley \& Knowles, 2016) to experience deep learning when problem-solving and computational skills are applied concurrently with understanding (Bati et al., 2018).

In this research, the STEAM integrated approach via Scratch was referred to as teaching science where arts, technology, mathematics, and engineering provide methods and contexts for learning the science. The aesthetics value of the art, namely artistic object, shape, color, sound, and movement of designed characters in the Scratch, provides the sensory and perceptual experience manipulation in students' minds and perception. Besides that, the aesthetics experiences include excitement, interest, eagerly in the process of artistic creation. In this context, the aesthetics experience in the STEAM integrated approach was focused on the art and the application of CT in the artwork creation process.

The samples in this research were required to design the electricity concept games based on the STEAM integrated approach, whereby the samples have been exposed to the opportunity to apply and enhance CT skills. The artwork in the game design made the research unique as aesthetic representations of scientific knowledge were used to understand the science concepts. The aesthetics value of art in STEAM facilitates students' scientific participation or discovery in aesthetics experience. As the art platform, Scratch was used to develop own aesthetic understanding from the design work based on the constructionism theory that parallels with Kalelioğlu and Gülbahar's (2014) study in using Scratch as the learning tool. The integration of art and the aesthetics framework in the art could be implemented either interdisciplinary or transdisciplinary framework (Hammer, 1996; Tan et al., 2020).

From the perspectives of arts and the sciences, the designed games represented a unique quantum of interpretation that made sense of external abstract signals (Tan et al., 2020). Applying art into the science lessons posed the same working method of scientists and artists in solving the problems. Scientists and artists apply observation, inspection, and reflection to analyze abstract environmental signals (Quigley \& Herro, 2016). Students experience the different perspectives of aesthetic experience in doing the aesthetic understanding, aesthetic analysis, and aesthetic learning through visualization. Thus, the applied STEAM integrated approach in this research emphasizes the aesthetic art experience in enhancing the science concepts learning, especially electricity concepts, and enhancing CT.

Students observe, inspect, reflect, and play during the game designing. Students visualize abstract concepts like voltage, current, and resistance in electricity concepts through the art. By reflecting on students' practice of designing games, students enhanced and gained their understanding by using the aesthetic tool to abstract reasoning and critical thinking (Hammer, 1996) in learning the electricity concept. The designed games were unique in their aesthetics presentation as the design combined works of art, formulas, electricity theories, or diagrams, but all of them have similarities in which those designing processes communicated abstract ideas in electricity content. It was parallel with Tan et al. (2020), and Hammer (1996), who incorporated art and aesthetics in the STEAM laboratories to enhance science education in an aesthetic framework. 
Designing activities provide a context for STEAM integration. The art is found to be more accessible electricity concepts learning and facilitate the mastering of the science idea in a meaningful and more manageable way (Tan et al., 2020). With the art integration in the electricity concepts lessons, students should grasp the bonding and interrelation of every component in electricity with art and reduce the learning issue. Applying art in an actual situation should direct students to the deeper learning (Tan et al., 2020) of the electricity concepts as the students are exposed to the opportunity to communicate content knowledge and information artistically. Therefore, games designing required creating and forming own understanding and making connections, especially the abstract nature of electricity concepts and reasoning required in electricity concepts learning (Gibbons et al., 2003; Tan et al., 2020) that is parallel with the constructionism theory. In games designing, the students' primary purpose was on the art usage in delivering electricity concepts to enhance their CT skills. The game designing project focused on the way students infused the art element with engineering and technology artistically in designing games. Students were needed to apply science and mathematics concepts to compute and modify the spirits steps (the character in Scratch) in the STEAM integrated approach via Scratch, whereby the CT skills were applied.

Visual, spatial, and graphic art can foster understanding of science concepts (Segarra et al., 2018), especially electricity concepts. Besides, Segarra et al. (2018) also agreed that visual art was the most prominent and popular art form when integrating art into STEM was proposed. Drawing served as a model for problemsolving with visual art by close observations to invoke a connection between function and form (Segarra et al., 2018). Segarra et al. (2018) showed that incorporating drawing activities into STEM learning helped students learn straightforwardly and thoroughly. The students reflect on their scientific experience and comprehension through drawing and painting (Segarra et al., 2018). Drawing fosters close observation, helps create relationships between function and form, and serves as a problem-solving model (Segarra et al., 2018). Learning, applying, and applying science and mathematics concepts occur as students work in teams to find solutions for real-world problems (Kang, 2019; Kelley \& Knowles, 2016).

McGrath and Brown (2005) strongly agreed with the potential of visual art in improving cognition in 'STEM' education. At the same time, the main findings by Henriksen (2014) also proved that art integration into STEM emerges to promote more motivation, participation, and concept-changing influence on the existing STEM-based learning. These studies described the strengthening and improvement of STEM discipline by integrating the art, making the study more holistic when using the right brain divergent thinking and left- brain convergent thinking (Bahrum et al., 2017). In addition to improving the core content, arts integration can be engaging and be the moment of pleasure and appreciation, of fun to learning (Bahrum et al., 2017; Segarra et al., 2018). It resulted in students under the STEAM education appearing to be more creative, have critical thinking, and work in teamwork, communicate, and solve problems in designing and implementing activities (Bahrum et al., 2017). Moreover, art integration into the STEM disciplines poses a high potential in promoting rigor and creativity while enabling multiple neural pathways with a higher probability of retaining knowledge (Bahrum et al., 2017; Land, 2013). Long-term results in retaining knowledge are achieved (Kang, 2019) as the visual arts activities promise enjoyable scientific experiences through scientific concepts' artistic creations (Segarra et al., 2018).

A real STEAM education also enhances students' understanding of applying science concepts and improving technologies and engineering (Psycharis, 2018). Engineering and technology in STEAM are simultaneously essential in preparing students to face challenges. According to the National Research Council (2012a, 2012b), engineering practices at the school level involve clarifying problems, designing and using models, planning and carrying out investigations, analyzing data, using mathematics and $\mathrm{CT}$, developing solutions, working in argument from evidence as well as obtaining, assessing, and analyzing information. The involvement of engineering and technology is due to the potential of engineering in nurturing creativity and logic-based mathematics and science (Yakman, 2008).

Hence, the application of engineering and technology in STEAM integrated approach in this research help in utilizing new knowledge innovatively in problemsolving that reflects what students learned and the effectiveness of the strategies employed in solving a problem. Moreover, engineering and technology involved in creating technology cause permanent changes to science, the natural elements that make up the universe (Yakman, 2008). The designing process incorporates intelligence, mind, and understanding human behaviour into scientific thinking (Wing, 2011). These STEAM integrated approach practices exposed students to the opportunities to solve engineering problems or challenges. Hence, the games designing process requires knowledge in art with the help of engineering and technology. In summary, science concepts can be learned with art, mathematics functions as the solving method, while engineering and technology work as the solving tool in learning in this STEAM integrated approach in the research.

\section{AIM AND RESEARCH QUESTIONS}

This research explored the effectiveness of using the STEAM integrated approach via Scratch to educate male 
and female students on the electricity concept to enhance CT skills. The following research questions were used to guide this study:

1. What are the mean score achievement of male and female students in CT, algorithmic thinking, cooperativity, creativity, critical thinking, and problem-solving skill?

2. Do differences exist in male and female students achievement in CT, algorithmic thinking, cooperativity, creativity, critical thinking, and problem-solving skill?

\section{METHODOLOGY}

\section{General Background}

A quasi-experimental design consisted of male and female groups was used in this research to study the effect of the STEAM integrated approach at the CT level. The CT subconstructs consisted of algorithmic thinking, cooperativity, creativity, critical thinking, and problemsolving skill after the intervention. The STEAM integrated approach via Scratch was used to conduct the lessons on electricity. The science application is applied when explaining the concepts of electricity. Technology application is made when students apply a technology product using Scratch to design games on electricity. Engineering application is made when the students design the games on electricity which evaluate the comprehension and the mastering the electricity concepts. Implementation of art is used to designing and explaining the electricity concepts by including elements such as writing, drawing, and conversation in Scratch. The mathematics application is applied to measure the movement of the characters in Scratch.

A pre-test was carried out before the intervention was conducted on both groups to identify the students' initial CT levels. Two months of intervention were given after the pre-test. The students were required to design games based on the electricity topic during the intervention, whereby the CT was evaluated throughout the design. The students have to show the ability to construct various question types to solve the game problems, work collaboratively, use creative thinking strategies in gamemaking and solve challenges besides the game designing process. Indirectly, the constructionist theory was applied when the students started investigating, creating, and solving problems. The students played the role of mathematicians and scientists when exploring and interacting with the virtual world through mathematics and science systems during game designing (Groff et al., 2010). Last but not least, the students must have the ability to act on constructional feedback with critical thinking and locate relevant information from various sources to solve game problems. Finally, a post-test was carried out on both groups of students to identify the teaching effect on increasing CT levels.

\section{Research Participants}

The research was undertaken involving two groups of students: 29 males and 30 females. Both groups had undergone the same intervention. The male and female groups were selected from different schools but with the same learning environment, namely, the daily school to avoid cross-contamination between the groups. Nevertheless, the instructors and teachers for male and female groups had a similar background in experience, qualifications, and socioeconomic status.

\section{Research Instrument}

The instrument used in the research was the CTS adapted from Korkmaz et al.'s (2017) CT scale. A fivepoint Likert scale, ranging from 1 (Never) to 5 (Always in CTS), was used to identify CT levels among the participants. The CTS evaluated and identified students' skills degrees and revealed the CT levels. According to Korkmaz et al. (2017), CT skills comprise five subconstructs: algorithmic thinking, cooperativity, creativity, critical thinking, and problem-solving (Doleck, 2017; Korkmaz et al., 2015). Subsequently, CTS used in the research consisted of 29 items from these five subconstructs. There were six algorithmic thinking items, four cooperative items, eight creativity items, five critical thinking items, and six problem-solving items.

Three different groups of people validated the CTS to determine the content validity and face validity. These people were professors in science and Information and Communications Technology (ICT), two expert English teachers, and fifteen lower secondary students. The researchers examined all the CTS items and decided on the convenient items. The two expert English teachers (with more than thirty years of English teaching experience) checked the CTS's grammar. Statements that were challenging to understand and misleading items were controlled and corrected by the two expert English teachers.

Simultaneously, the formed draft was examined by 15 students whose comments were taken beforehand. They were interviewed to determine how difficult the items' were to understand and their perception of each item. The interview ensured that the items were thoroughly understood and prevent any misunderstanding of the sentence's meaning. A pilot test was staged to identify and correct the instruments' weaknesses and establish the reliability to achieve face validity. The reliability index for the CTS was computed using Cronbach's alpha. Scores were coded, summed, and transformed to a scale from 1 (never) to 5 (always) for each parameter. The Cronbach's alpha coefficients were 0.84 in the CTS reliability studies, suggesting that the items had a relatively high internal consistency. 
Cronbach's alpha coefficients were calculated for each scale of the five subconstructs of CT: algorithmic thinking, cooperativity, creativity, critical thinking, and problem-solving to determine the reliability values. The values were found to be between 0.73 and 0.76 . The items' total correlation coefficients score were also individually estimated for each scale. The values were identified as: algorithmic thinking (between 0.47 and 0.73), cooperativity (between 0.69 and 0.90), creativity (between 0.79 and 0.89 ), critical thinking (between 0.57 and 0.78), and problem-solving (between 0.62 and 0.79).

\section{Intervention}

The intervention was implemented in two lessons for every week in three (3) months times. Each lesson lasted for 90 minutes. Both male and female groups underwent the same intervention with the same science teacher with years of teaching experience. Both groups of students were instructed with the STEAM integrated approach using Scratch. During the intervention, Scratch was used to deliver the electricity concept content knowledge and the way of using Scratch. After the lessons, every two students were grouped into a group. Then, students were required to design the electricity games, whereby students have the opportunity to apply the five subconstruct of $\mathrm{CT}$ during the design by integrating the STEAM element simultaneously. The game design combined works of art, formulas, electricity theories, and diagrams, but all of them served the same purpose in communicating the abstract concepts in electricity. After the intervention, the EAT instrument was applied to evaluate students' $\mathrm{CT}$ and five $\mathrm{CT}$ subconstructs.

\section{Data Analysis Procedure}

Three tests were used in testing the research hypotheses: (a) paired sample t-test, (b) repeated ANOVA measure and analysis of covariance (ANCOVA), and (c) a one-way repeated measure MANOVA. A paired sample t-test was conducted to test the differences in CT levels for the two different groups. The ANOVA repeated measure and ANCOVA were undertaken to test group differences gradually on the $\mathrm{CT}$ score. One-way repeated measure MANOVA was conducted to test the differences in the five subconstructs of the CT. The MANOVA enables the test of hypotheses on the effect of the STEAM integrated approach on five subconstruct of CT simultaneously. Additionally, the MANOVA distinguishes whether statistical differences exist in the interaction between test time and the CT subconstructs. A pre-CT test was defined as a covariate to eliminate the original students' CT level variation.

\section{Data Analysis}

Descriptive data were calculated for each dependent and independent variable groups. The descriptive analysis included the number, mean, and standard deviation. Thus, two MANOVAs were completed. The first MANOVA determined the differences between males and females in achievement percentage of CT. In contrast, the second MANOVA was conducted to investigate possible CT percentage differences and among the five subconstructs of CT.

The first step was to conduct descriptive statistics to determine the achievement percentages of $\mathrm{CT}$ and five CT subconstructs for male and female students. The descriptive analysis presented the number, mean percentages, and standard deviations for male and female students in answering the research questions. The second step was substantial and tested the null hypothesis and determined that no significant differences exist for the two groups of students. Therefore, the second step was focused on completing follow-up tests to explain the group differences in CT and the five CT subconstructs. A paired sample t-test, ANCOVA, MANOVA was used in this research to analyse the five subconstruct of CT.

As with other statistical procedures, the research data proven satisfy certain assumptions for the work procedure, especially with the meaningful $p$ values $(p<$ .05). The data form a proper statistical random sample from an underlying population. The dependent variables have a normal distribution which was proved by Shapiro -Wilk test and Skewness and Kurtosis, on the pre-test and post-test on CTS and five subconstruct of $\mathrm{CT}$, were normally distributed for both male and female students ( $>0.05)$, whereas Wilk's Lambda $=.70, \mathrm{~F}(5,53)$ $=4.54, \mathrm{p}<.05$. Wilks' Lambda test of statistical significance was applied. The probability value for gender effects was less than $.05(p<.05)$, then the effects were significant. A meaningful Pearson correlation pattern was observed among the dependent variables $(\mathrm{p}$ $<.05)$, and Box's M value of 21.78 with $\mathrm{p}=.18$. Therefore, the covariance matrices between the groups were assumed to be equal in MANOVA. Finally, Levene's test verified the equality of homogeneity of variance for each dependent variable $(p>.05)$, and the correlation between the dependent variables is identical in all groups of observations.

\section{RESULTS}

The first research question addressed in this research was:

Q1: What are the means score achievement of male and female students in $\mathrm{CT}$, algorithmic thinking, cooperativity, creativity, critical thinking, and problem-solving skill?

The descriptive data generated the mean and standard deviation of the pre-CT and post-CT tests for the male and female students. The mean and the standard deviation for the male students in the pre-CT test was 57.66 and 8.06 , whereas post-CT values were 
Table 1. Mean and standard deviation for the pre-computational thinking and post-computational thinking test of male and female students

\begin{tabular}{lllcc}
\hline & Gender & Mean & Standard deviation & N \\
\hline Pre-CT & Male & 57.66 & 8.06 & 29 \\
Post-CT & & 92.90 & 6.53 & \\
\hline Pre-CT & Female & 56.80 & 7.44 & 30 \\
Post-CT & & 94.77 & 6.01 & \\
\hline
\end{tabular}

Table 2. Descriptive statistic for the pre-computational thinking and post-computational thinking test of five subconstructs of computational thinking: algorithmic thinking, cooperativity, creativity, critical thinking and problem solving

\begin{tabular}{|c|c|c|c|c|c|}
\hline & \multicolumn{3}{|c|}{ Pre-test } & \multicolumn{2}{|c|}{ Post-test } \\
\hline & Gender & $\mathrm{M}$ & SD & $\mathrm{M}$ & SD \\
\hline \multirow[t]{3}{*}{ Algorithmic thinking } & Male & 9.59 & 2.13 & 17.41 & 3.10 \\
\hline & Female & 10.93 & 2.74 & 19.17 & 2.72 \\
\hline & Total & 11.27 & 2.53 & 18.31 & 3.02 \\
\hline \multirow[t]{3}{*}{ Cooperativity } & Male & 9.83 & 2.38 & 10.24 & 2.23 \\
\hline & Female & 7.67 & 2.04 & 12.23 & 2.32 \\
\hline & Total & 8.73 & 2.45 & 11.25 & 2.47 \\
\hline \multirow[t]{3}{*}{ Creativity } & Male & 12.72 & 3.73 & 25.93 & 2.34 \\
\hline & Female & 10.93 & 2.78 & 23.87 & 2.80 \\
\hline & Total & 11.81 & 3.38 & 24.88 & 2.77 \\
\hline \multirow[t]{3}{*}{ Critical thinking } & Male & 8.79 & 1.84 & 15.10 & 3.42 \\
\hline & Female & 9.90 & 2.06 & 16.83 & 2.69 \\
\hline & Total & 9.36 & 2.02 & 15.98 & 3.17 \\
\hline \multirow[t]{3}{*}{ Problem-solving } & Male & 10.28 & 2.42 & 16.90 & 3.56 \\
\hline & Female & 8.93 & 2.49 & 18.57 & 1.94 \\
\hline & Total & 9.59 & 2.53 & 17.75 & 2.95 \\
\hline
\end{tabular}

92.90 and 6.53. Comparably, the mean and standard deviation for the female students in the pre-CT test was 56.80 and 7.44, while post-test CT values were 94.77 and 6.01 (Refer to Table 1). The achievement data were segregated according to the five subconstructs of CT (Refer to Table 2). The descriptive analysis provided indepth details on male and female students' capabilities in CT and five subconstructs of CT. When evaluating students' CT skills, no significant group differences are identified. Development of CT and five subconstruct of CT skills happens in the same way for both male and female group independently. The mean score for both male and female students of the pre-test is smaller than the post-test. Simultaneously, the mean score of the five subconstruct of CT kept increasing from pre-test to the post-test.

In algorithmic thinking, the male showed 7.82, and the female showed an 8.24 increment in the means score. Females showed more increment than males in algorithmic thinking. On the other hand, in the cooperativity, males and females showed the 0.14 and 4.56 increment, respectively, and the comparison showed that females improved in cooperative learning. Simultaneously, the increment can be observed in the creativity whereby males record the 13.21 and females 12.94 increments in the mean score. Male students seem to enhance their creativity more than females.

Meanwhile, male and female students displayed a 6.31 and 6.93 increment in the critical thinking means to score, which is almost the same. Maybe both groups of the students were exposed to the same environment in designing the problem-solving methods. Finally, for the last CT subconstruct- problem-solving, male and female students also present the means score increment. It was found that increment problem-solving skills among males and females is 6.62 and 9.64, respectively. To conclude, both males and females showed the increment in the five CT subconstruct, but the females displayed the total increment more than males.

The second research question addressed in this study was:

Q2: Do differences exist in the achievement of male and female students in CT, algorithmic thinking, cooperativity, creativity, critical thinking, and problem-solving skill?

\section{Differences in Computational Thinking among Male and Female Students}

A paired sample t-test was carried out to test the significant difference between CT's pre-test and post-test scores for male and female students. The result of the paired $\mathrm{t}$-test for male students was significant at $\mathrm{t}(28)=$ -21.25, $\mathrm{p}<.05$ (two-tailed), $\mathrm{\eta} 2=.94$, since $\mathrm{p}<.05$ (Refer to Table 3), and confirmed a significant difference between the pre-test and post-test for male students. Based on Cohen's guidelines (1988) and Sawilowsky (2009), this effect size was huge, implying a significant increase in CT level for males from the pre-CT test (mean 
Table 3. Paired samples t-test between the pre-computational thinking and post-computational thinking test of male and female students

95\% Confidence Interval

of the Difference

\begin{tabular}{lcccccccc}
\hline $\begin{array}{l}\text { Pre-CTS } \\
\text { Post-CTS }\end{array}$ & Mean & Std. Deviation & $\begin{array}{c}\text { Std. Error } \\
\text { Mean }\end{array}$ & Lower & Upper & t & df & $\begin{array}{c}\text { Sig. (Two- } \\
\text { tailed) }\end{array}$ \\
\hline Male & -35.24 & 8.93 & 1.66 & -38.64 & -31.84 & -21.25 & 28 & .00 \\
Female & -37.97 & 9.68 & 1.77 & -41.48 & -34.35 & -21.49 & 29 & .00 \\
\hline
\end{tabular}

Table 4. Results of one-way ANCOVA for significant difference between male and female students' computational thinking level at post-computational thinking test

\begin{tabular}{lcccccc}
\hline Source & $\begin{array}{c}\text { Type III Sum of } \\
\text { Squares }\end{array}$ & df & Mean Square & F & Sig. & $\begin{array}{c}\text { Partial Eta } \\
\text { Squared }\end{array}$ \\
\hline Corrected Model & $54.46^{\mathrm{a}}$ & 2 & 27.23 & .68 & .51 & .02 \\
Intercept & 8952.48 & 1 & 8952.48 & 223.90 & .00 & .80 \\
Pre-test & 2.89 & 1 & 2.89 & .07 & .79 & .00 \\
Gender & 54.27 & 1 & 54.27 & 1.36 & .02 \\
Error & 2239.16 & 56 & 39.99 & & \\
Total & 521927.00 & 59 & & & \\
Corrected Total & 2293.63 & 58 & & & \\
\hline
\end{tabular}

$=57.66$, standard deviation $=8.06)$ to the post-test $($ mean $=92.90$, standard deviation $=6.53$ ). The rise in mean was 35.24 , with a $95 \%$ confidence level interval for differences between -38.64 (lower bound) to -31.84 (upper bound), denoting a significant difference between the pre-CT and post-CT tests for male students.

Contrastingly, the paired t-test results were found to be significant at $\mathrm{t}(29)=-21.49, \mathrm{p}<.05$ (two-tailed), $\mathrm{n} 2=$ .94 , since $\mathrm{p}<.05$, confirming a significant difference (Refer to Table 3), confirmed a significant difference between the pre-test and post-test for female students. Based on Cohen's guidelines (1988) and Sawilowsky (2009), this effect size was huge, implying a significant increase in CT level for females from the pre-CT test $($ mean $=56.80$, standard deviation $=7.44)$ to the post-CT test $($ mean $=94.77$, standard deviation $=6.01$ ) was observed for female students. The rise in mean was 37.97, with a 95\% confidence level interval for differences between the means of -41.58 (lower bound) to -34.35 (upper bound). Therefore, the results exhibited a significant difference between the pre-CT and post-CT tests for female students. Conclusively, a significant difference was evident between pre-CT and post-CT tests for both males and females. Both groups of students gained a significant increase in the achievement of CT after the intervention. Based on the rise in mean, female students displayed higher increment in CT compared males.

Further analysis between both genders in the post-CT test was undertaken as differences were identified in pre-CT and post-CT tests. The ANCOVA finding showed that no statistically significant difference were found between male and female students in CT values $[\mathrm{F}(1,56)=1.36, \mathrm{p}>0.05$ (two-tailed), np2 (partial eta squared $)=.02]$ (Refer to Table 4$)$. In line with Cohen's (1988) and Sawilowsky (2009) guidelines, the effect size
(0.02) indicated a small magnitude effect $(2.0 \%)$ of the variance in the dependent variable that was explainable by the independent variable (Cohen, 1988; Sawilowsky, 2009).

Using one covariant variable analysis technique, by controlling prior knowledge towards the linear relationship between previous $\mathrm{CT}$, it shows significance score which is less than 0.05 . If viewed the influence of STEAM integrated approach towards male and female students' CT skill, it seems that significance score (group division) for STEAM education approach on CT skill is 0.02 . Since the score is less than 0.05 , so it can be concluded that without the influence of prior knowledge, on the credibility level of $95 \%$, there is an influence of STEAM integrated approach on towards CT skill. The effect of students' prior knowledge and STEAM integrated approach towards students' CT skill simultaneously can be seen from significance number on Corrected Model. It can be seen that a significant amount is 0.02 . Since the significant number is less than 0.05 , so it implies that simultaneously student's prior knowledge and type of learning used influence CT skill.

The actual difference between mean scores of CT was also indicated by the posthoc analysis, where the mean and standard deviation for male students were 92.90 and 6.53. The mean was 94.77 , and the standard deviation was 6.01 for female students (Refer to Table 1) despite the statistical significance. Consequently, the STEAM integrated approach via Scratch effectively enhanced the CT level in male and female groups. Both groups showed positively similar results in increasing the CT level. 


\section{Differences in the Five Subconstructs of Computational Thinking among Male and Female Students}

The data in the Test of Between-Subject Effect were analysed to study how the dependent variables: algorithmic thinking, cooperativity, creativity, critical thinking, and problem-solving differ in both genders. According to the MANOVA findings, the interaction effect was statistically not significant for algorithmic thinking $\left(W_{i l k s}^{\prime}\right.$ Lambda $=.90, \mathrm{~F}(5,48)=1.13 ; \mathrm{p}>.05$; partial $\eta 2=.09$ ), cooperativity (Wilks' Lambda $=.96, \mathrm{~F}$ $(5,48)=.35 ; \mathrm{p}>.05 ;$ partial $\eta 2=.17)$, creativity (Wilks' Lambda $=.94, \mathrm{~F}(5,48)=.63 ; \mathrm{p}>.05 ;$ partial $\mathrm{\eta} 2=.14)$, critical thinking (Wilks' Lambda $=.98, \mathrm{~F}(5,48)=.16 ; \mathrm{p}>$ .05 ; partial $\eta^{2}=.08$ ) and problem-solving (Wilks' Lambda $=.93, \mathrm{~F}(5,48)=.76 ; \mathrm{p}>.05 ;$ partial $\eta 2=.08)$ (Refer to Table 6). The between-subjects effects revealed no statistically significant difference in CTS among male and female students' for the five subconstructs of CT ( $\mathrm{p}$ $>$.05).

In summary, both male and female students demonstrated a positive tendency to increase CT level and the five CT subconstructs. All the five subconstructs of CT increased simultaneously and proved that both genders have equality in gaining CT skills and learning electricity concepts. Female and male students displayed the potential in applying the STEAM element in enhancing the CT skills when studying the electricity concepts.

\section{DISCUSSION}

The current research analyzed male and female students' CT skills in designing electricity concepts games, emphasizing the STEAM integrated approach's impact on different gender student groups. The research results provide sufficient evidence from evaluation CTS instruments administered before and after the intervention, thus offering a clear idea of how CT skills develop as students' designing progresses. The research indicates that the STEAM integrated approach via Scratch had successfully supported both male and female students' five subconstruct of CT skills. Both male and female students showed increased CT skills and could apply all five subconstruct of CT during the game's development.

In answering Research Question 1, the research finding shows that the intervention positively increased both the male and female students' CT skills and five CT subconstructs (Tables 1 and 2). Table 1 illustrates a change in students' $\mathrm{CT}$ and the other five subcontract $\mathrm{CT}$ skills patterns. In Table 1, before treatment using the STEAM integrated approach method, male students are still at an average level of 57.66, and female students are still at an average level of 56.80 for the CT application level. Before the intervention, both genders of students were still not familiar with using visual learning media with Scratch. They found it difficult to express the understanding of electricity through the art or was still elementary level in algorithmic thinking, cooperative, creative, critical thinking, and problem-solving patterns. In the pre-test, both gender students faced difficulty understanding and applying the CT skills, which was proven by the low means scores. The concepts of application of CT skills in solving problems appear blur among most of the students. The students had no confidence in applying CT to solve the problems during the lessons. Consequently, the high value of the standard deviation for the male and female students shows the vast difference among the students on the CT skills application.

Nevertheless, both male and female students scored high in the post-CT test after the intervention using the STEAM integrated approach method. The number of male and female students who showed the CT skills capability in games designing on electricity concepts increased. Both male and female students independently develop the same CT skills at the end of their intervention. The data showed a significant increment in the mean score of post-CT results compared with the low mean score in the pre-CT test. Students underwent an increase in their CT skills patterns by an average mean score of 92.90 and 94.77 , respectively, on male and female students, where there is an increase in the difference of 35.24 points at male students and 37.97 points at female students. This proves that the STEAM integrated approach method had positively impacted the ability to apply $\mathrm{CT}$, namely producing interactive games in explaining the electricity concepts. Meanwhile, both genders of students also exhibit enormous progress in mastering the five CT subconstruct in problem-solving.

Table 2 shows that the five subconstruct of CT improvement among the male and female students in the post-CT test is higher than the pre-CT test. The mean difference test results indicate a significant difference in five subconstructs of CT skills before and after the intervention. The big improvement of students' five subconstructs of CT skills in both gender groups can be explained by the STEAM integrated approach and learning process on each group during learning. The most remarkable improvement was achieved in the subconstruct creativity, whereby males record the 13.21 and females record the 12.94 increments in the mean score. The lowest increasement was achieved in the subconstruct cooperativity. The ability to apply CT was tested in designing games with Scratch. The research finding indicated that the STEAM integrated approach via Scratch successfully increased five subconstruct of CT (based on Table 2), which also parallel with Bell and Bell (2018) and Psycharis (2018) finding. So, the STEAM integrated approach to learning electricity concepts positively impacts the increase of students' $\mathrm{CT}$ and five subconstructs of $\mathrm{CT}$ thinking skills. The increase of students' CT and five subconstruct of CT skills can be 
identified from each indicator given when pre-test and post-test commonly increase in both gender groups.

Both male and female groups showed an increment in post-CT and the capability to apply five CT subconstruct in solving problems when designing games. The wide application of these five CT subconstructs, namely algorithmic thinking, cooperativity, creativity, critical thinking, and problemsolving (Korkmaz et al., 2017) among males and females, were observed during the design of the games. Students developed the information, tested the solutions, evaluated existing CT to create new games, and expanded current CT. The CT focused on students' ways of solving problems rather than working like a machine in this research. The innovative use of CT sets deepened science's content learning, especially electricity concepts, as agreed by Weintrop et al. (2016). The CT being nurtured in this aesthetics-based research during the construction of knowledge based on constructionism theory. From the moment students get involved in comprehending the problems by thinking, analyzing, and diagnosing the types of issues in designing the games, they are already involved in constructionism learning with art. Students started learning in a constructionist way when exploring surroundings and construct interpretation with problem-solving through games designing in aesthetics environment.

These five subconstruct were significantly displayed among the students during the games designing process. For the first subconstruct, algorithmic thinking can break down a problem logically and methodically compose a suitable algorithm by understanding, applying, assessing, and producing the algorithms (Korkmaz et al., 2017). During the games designing process, the students focused on using this algorithmic thinking to draft out every step and movement of the characters in the games to have a smooth flow and implement strategies to solve problems. Students who have mastered algorithmic thinking showed the ability to analyze the gained data on electricity concepts, make an affirmation, and draw conclusions based on their analysis findings (Weintrop et al., 2016). The algorithmic improvement thinking and problem-solving through the element of science in STEAM integrated approach consisted of students' ability to explain the electricity concepts and interpret data, numbers, and words scientifically and orderly with algorithmic thinking to solve the content knowledge understanding problems. The application of the scientific concept in game design was closely related to the indicator of application algorithmic thinking, problem-solving through the STEAM integrated approach that applies the principles of science, technology and develops solutions to achieve the target in designing the games.

For the second CT subconstruct, cooperativity has gained popularity among the learning method to contribute to academic success, share knowledge, and construct social relationships (Korkmaz et al., 2017). In this research, cooperative learning significantly influences students to work collaboratively to identify the required skills in solving a problem. Students showed the capability to analyze a problem they faced from multiple perspectives or produce multiple solutions through information sharing during cooperative learning after the intervention. Cooperative learning engaged students in self-directed learning in STEAM integrated approach activities lead and enhances students' communication competency and motivation to learn. Besides that, the other CT subconstruct, like creativity, critical thinking, and problem-solving, were also widely applied during game designing. When students think critically, they also think deeply; they understand the facts, but they take the extra step of going beyond the facts to do something with them.

Visualization is one of the most popular among the different modes of aesthetic representations of scientific knowledge (Hammer, 2014). It was proven through lots of researches to explore the role of images in science from different perspectives (Adelmann et al., 2009; Borrelli \& Grieser, 2017; Frappier et al., 2013; Halpern, 2014). The visualization represents the essence of all scientific activity. It can be concluded that scientists use an aesthetic way (visualization way) to bring understanding in the specimens, genetic sequence, or an undefined protein (Borrelli \& Grieser, 2017). The product of scientific or artistic work represents how the problems were solved. Concurrently, abstract concepts learning appeared to be more meaningful and engaging. The complex of decisions, activities, and processes that comprise an aesthetic can be considered the bridge linking the abstract world we sense with the ordered world that we articulate (Hammer, 2014). Hence, the STEAM approach in learning does not only help teach science concepts but also enables students to think and work with art and science simultaneously, inspiring students to become more different and become creative and critical thinkers across disciplines.

The activity of games designing that applies electricity concepts requires students to be able to think critically and creatively in overcoming any obstacles found in the game-making process. In other words, there were no more memorization and recall of factual information during the learning process. Students were exposed to the opportunity required to make the wellreasoned evaluative aesthetics judgment. Students analyzed, evaluated, or make judgments during critical thinking problem-solving and reached the final decision. Students' solving problems reflected that students had manipulated the skills in putting theory into practice when directly involved in generating, analyzing, and evaluating the best solutions. As a principle for putting theory into practice in learning and its approach, Papert's constructionism serves as the guiding principle 
in the future for curriculum design, materials development, and classroom practice. The capability of employing the CT and five subconstruct of CT works as good indicators of understanding the effectiveness of using STEAM integrated approach to develop solutions to achieve the learning objectives. The CT application enables the students to propose creative, algorithmic solutions and alternatives and decide the suitable solution for the problems. Hence, creating and designing the games that train students' CT is carried out along the intervention. Therefore, students need creativity and critical thinking to develop solutions to achieve goals.

In answering Research Question 2, the research finding proved no significant difference among the male and female group students in CT with the STEAM integrated approach (Table 3 and 4). Simultaneously, no significant differences were identified in the linear combination of the mean for the post-test mean score in CT among the male and female students who followed the STEAM integrated approach via Scratch. All five subconstructs of CT showed a similar positive effect for both groups of students. Both groups of students managed to show a significant increment in CT and the five subconstructs of CT. Both genders also showed a statistically significant relationship with the combined dependent variables. Besides, the five subconstructs of CT were analysed with the probability value for gender at less than .05 (Wilks' Lambda $=.63, \mathrm{~F}(5,53)=6.13$; $\mathrm{p}<$ .05 ; partial $\eta 2=.37$ ). The students were found to have acquired the CT skills and enhanced the application of CT skills and five subconstruct of CT in understanding the concept of electricity, such as calculating the electric current, resistance, and the construction of the electric circuit.

All the five CT subconstruct showed the favourable linear combination and interrelated under CT in enhancing both males and females. In other words, all these subconstruct algorithmic thinking, cooperativity, creativity, critical thinking, and problem-solving show equal importance. The linear combination of the mean for post-test mean score of construct algorithmic thinking, cooperativity, creativity, critical thinking, and problem-solving in CT positively impacts both males and females learning electricity concepts. No gender is left behind in learning and has equal opportunity in the application of CT skills. The five CT subconstruct functions well in improving the total CT skills by being implemented together to solve the problem during games designing. The research finding shows no significant difference between all these five CT subconstruct among males and females on the post-CT (Table 4). The research also showed that gender had a statistically significant relationship with $\mathrm{CT}^{\prime} \mathrm{s}$ five subconstructs. Both genders showed the capability of applying all the CT skills together in problem-solving during learning.
Moving on to Table 4, in evaluating students' CT skills, no between-group differences are identified. It is proven by analysis by using the ANCOVA test. The results showed a difference of influence that is convincing between prior knowledge and the student's CT skill. In answering the second research question, the research finding showed that the intervention had a similar positive effect in increasing both male and female CT and all the five subconstructs of CT (Table 3). The results of the hypothesis analysis test in Table 3 show that: $t$-count for male students is 21.25 , and the $t$-count for female students is 21.49 and Sig. (2-tailed) indicates that Sig. (2-tailed) count $<0.05$. Explained a change in both gender students' CT abilities using the STEAM integrated approach method. This analysis explains that the learning method uses the STEAM integrated approach method, and students are invited to continue improving their CT.

It can be seen from the increase in the average CT learning outcomes before and after with an increase in the difference of 35.24 points at male students and 37.97 points at female students from the average before using the STEAM integrated approach method in learning. The increase in the average learning outcomes shows that the STEAM integrated approach method is reliable because each student can develop CT in testing or application of knowledge. In this case, the making of games based on technology and images and language (art) in mathematical analysis, in the form of a scale or a pause between one animated image slide and language with another so that it is easy to understand the delivery of the learning. The analysis of hypothesis testing using the t-test shows that the ability to think CT on games designing assignments has increased by 21.25 and 21.49 , by the involvement of students directly start from the preliminary stage (needs analysis, use of appropriate media methods), the stage of making learning games, the product testing stage until the final stage of product strengthening.

Although males and females reach the same CT skills level (ANCOVA in Table 4), there is, however, a significant difference between cooperativity and problem-solving for the female, indicating that the female does learn more in the cooperative learning with peers and exchange the problem-solving method in order to find the best solution for the problems. This difference is also reflected in the male post-test, but just the difference is not so apparent as females do (Table 3). Students gave feedback through comments on projects, worked together on collaborative projects, remixed one project with another, crowd-sourced artwork for their projects, and designed games to share their new knowledge. The female students' ability to acquire problem-solving skills in connecting with daily life and utilizing new technologies is valuable to meet the 21stcentury requirements (Lin et al., 2021). STEAM refers to the intersection of sciences and arts that incorporates 
skills, including languages and liberal arts, such as sociology, philosophy, history (Yakman, 2010), or specific artistic disciplines such as design, creative writing, or visual and performing arts (Iglesias et al., 2018).

The potential of art in reducing gender inequality in STEAM is quite tangible (OECD, 2018). Connecting art to science makes learning more effective and innovative (Liliawati et al., 2018) and supports equal opportunities among males and females. More female students showed the capability to use CT to solve electricity concept game designing problems after the intervention. Ruiz-Mallén et al. (2017) also agreed that the involvement in the artistic experience enables the retain more females in science learning. Hence, the STEAM integrated approach enables the transformation of the theoretical knowledge into practice and creating an environment for the design and product development as agreed by Tunc and Bagceci (2021), as well as nurture the problem-solving skills in order to prepare students in placing the thinking and exploration in daily life (Gunawan \& Shieh, 2020). Students' experience in the calculation (Mathematics) is also being enhanced when students learn about the electric current in the circuit. Eventually, students improved the electricity concepts content knowledge and used general thinking to solve a problem mathematically.

The aesthetic form of learning through the art experience occurred at its best when students were encouraged to understand their surrounding world independently by aesthetic represent all the electricity concepts via Scratch. When students are asked to provide evidence of CT skills, they appear to perform very well in applying all the five subconstruct of $\mathrm{CT}$ in designing the games on electricity concepts. Students thoroughly express their five CT subconstructs required to describe a generalized problem solution. The STEAM integrated approach via Scratch provided authentic learning when developing the actual product (Sahin et al., 2014). In this research, the actual products, designing games which contained one discipline and integrated with other disciplines, like science, technology, engineering, art, and mathematics. The STEAM integrated approach opened up a new way of seeing, thinking, and learning (Psycharis, 2018) with the aesthetics art experience. Students had learning opportunities to transcend five different disciplines and enrich their learning (Hetland, 2013; Psycharis, 2018). Besides, students strengthened their disciplinary knowledge across another domain and got the opportunity to explore and connect art, science, and others (Henriksen, 2014). Through STEAM's learning to train the talents to face the problems of the 21st century (Boy, 2013; Liliawati et al., 2018; Piro, 2010).

In short, in this research, the applied learning strategies influence the increase of CT and the five subconstructs of CT. The emphasize on the aesthetic value of art in STEAM integrated approach via Scratch made the male and female students learn and work the STEAM elements, inspiring them to be more creative and innovative thinkers across disciplines. They indirectly grew up as creative thinkers when students create characters and storylines in their games. They used their imaginations to explore new ideas and directions, parallel with constructionist theory, whereby learners construct new knowledge by learning.

\section{CONCLUSION}

Based on the analysis and discussion results, STEAM integrated approach learning through the games designing project on electricity concepts that has been implemented has a significant effect on the improvement of students' CT skills and five subconstruct of CT. Both male and female students showed equal ability in applying CT and five subconstruct of CT after the STEAM integrated approach intervention. Both genders of students showed the mastering skills on the electricity concepts through the aesthetics experience through game's development after the invention. Indirectly, the art experience in learning promoted gender equality and proved that both males and females equally showed CT skills. Through the research finding, data had proven that art integration in the STEAM integrated approach posed a significant positive impact and influence in learning the science concepts, CT skills, and five subconstruct of CT. Nevertheless, the limitation of the current research was focused on applying the STEAM integrated approach in learning on a specific science topic, rather than on the close study across different and variety theme of science topics. This means that researchers currently know relatively little about the STEAM integrated approach on other different science topics. Hence, future research could be conducted to serve the real purpose of STEAM implementation in the different theme of science topics, then examine how successful the STEAM integrated approach is in helping students' in science learning with art integration.

Author contributions: All authors have sufficiently contributed to the study, and agreed with the results and conclusions.

Funding: The authors would like to express their gratitude to Ministry of Higher Education Malaysia (MOHE) for the funds provided under the TIER1 Grant (H842) through Research Management Center (RMC), Universiti Tun Hussein Onn Malaysia (UTHM).

Declaration of interest: No conflict of interest is declared by authors.

\section{REFERENCES}

Adelmann, R., Jan Frercks, M. H., \& Hennig, J. (Eds.), (2009). Datenbilder. Zur digi-talen Bildpraxis in den Naturwissenschaften [Data images. On digital image practice in the natural sciences] (Bielefeld, transcript).

https:/ / doi.org/10.14361/9783839410417 
Anderman, E. M., Sinatra, G. M., \& Gray, D. L. (2012). The challenges of teaching and learning about science in the twenty-first century: Exploring the abilities and constraints of adolescent learners. Studies in Science Education, 48(1), 89-117. https: / / doi.org/10.1080/03057267.2012.655038

Baek, Y. S., Park, H. J., Kim, Y. M., Noh, S. G., Park, J. Y., Lee, J. Y., \& Han, H. (2012). A study on the action plans for STEAM education. KOFAC (Korea Foundation for the Advancement of Science \& Creativity) Report, 12.

Bahrum, S., Wahid, N., \& Ibrahim, N. (2017). Integration of STEM education in Malaysia and why to STEAM. International Journal of Academic Research in Business and Social Sciences, 7(6), 645-654. https:/ / doi.org/10.6007/IJARBSS/v7-i6/3027

Bati, K., Yetişir, M. I., Çalişkan, I., Güneş, G., \& Saçan, E. G. (2018). Teaching the concept of time: A steambased program on computational thinking in science education. Cogent Education, 5(1), 1507306. https:/ / doi.org/10.1080/2331186X.2018.1507306

Belbase, S., Mainali, B. R., Kasemsukpipat, W., Tairab, H., Gochoo, M., \& Jarrah, A. (2021). At the dawn of science, technology, engineering, arts, and mathematics (STEAM) education: Prospects, priorities, processes, and problems. International Journal of Mathematical Education in Science and Technology, 1-37. https://doi.org/10.1080/ 0020739X.2021.1922943

Bell, J., \& Bell, T. (2018). Integrating computational thinking with a music education Context. Informatics in Education, 17(2), 151-166. https: / / doi.org/10.15388/infedu.2018.09

Bers, M., \& Horn, M. (2010). Tangible programming in early childhood: Revisiting developmental assumptions through new technologies. In I. Berson \& M. Berson (Eds.), High-tech tots: Children in a digital world (pp. 49-70). Information Age Publishing.

Bertrand, M. G., \& Namukasa, I. K. (2020). STEAM education: student learning and transferable skills. Journal of Research in Innovative Teaching \& Learning. https:/ / doi.org/10.1108/JRIT-01-2020-0003

Borrelli, A., \& Grieser, A. (2017). Recent research on the aesthetics of knowledge in science and in religion. Approaching Religion, 7(2), 4-21. https:/ / doi.org/10.30664/ar.67710

Boy, G. A. (2013). From STEM to STEAM: Toward a human-centered education, creativity \& learning thinking. In Proceedings of the 31st European Conference on Cognitive Ergonomics, Belfast, UK (pp. 1-7). https:/ / doi.org/10.1145/2501907.2501934

Brodland, G. W. (2015). How computational models can help unlock biological systems. Seminars in Cell $\mathcal{E}$
Developmental Biology, 47-48, 62-73. https://doi.org/10.1016/j.semcdb.2015.07.001

Brophy, D. R. (1998). Understanding, measuring, and enhancing individual creative problem-solving efforts. Creativity Research Journal, 11(2), 123-150. https://doi.org/10.1207/s15326934crj1102_4

Buitrago Flórez, F., Casallas, R., Hernández, M., Reyes, A., Restrepo, S., \& Danies, G. (2017). Changing a generation's way of thinking: Teaching computational thinking through programming. Review of Educational Research, 87(4), 834-860. https:/ / doi.org/10.3102/0034654317710096

Chevalier, M., Giang, C., Piatti, A., \& Mondada, F. (2020). Fostering computational thinking through educational robotics: A model for creative computational problem solving. International Journal of STEM Education, 7, 39. https:/ / doi.org/10.1186/s40594-020-00238-z

Cimpian, J. R., Kim, T. H., \& McDermott, Z. T. (2020). Understanding persistent gender gaps in STEM. Science, 368(6497), 1317-1319. https://doi.org/ 10.1126 / science.aba7377

Cohen, J. (1988). Statistical power analysis for the behavioral Sciences (2nd ed.). Eribaum.

Conde, M. Á., Ferández-Llamas, C., Ribeiro Alves, J. F., Ramos, M. J., Celis Tena, S., Gonçalves, J., .Lima, J., Reimann, D., Jormanainen, I., \& García-Peñalvo, F. J. (2019). RoboSTEAM - A challenge based learning approach for integrating STEAM and develop computational thinking. In M. Á. Conde-González, F. J. Rodríguez-Sedano, C. Ferández-Llamas, \& F. J. García-Peñalvo (Eds.), TEEM'19 proceedings of the seventh international conference on technological ecosystems for enhancing multiculturality (Leon, Spain, October 16th-18th, pp. 24-30). ACM. https:/ / doi.org/10.1145/3362789.3362893

Curzon, P. (2015). Computational thinking: Searching to speak. https:/ / teachinglondoncomputing.org/freeworkshops/computational-thinkingsearching-tospeak/

Curzon, P., Black, J., Meagher, L. R., \& McOwan, P. (2009). Enthusing students about computer science. Proceedings of Informatics Education Europe IV, 73-80.

Denning, P. J. (2009). The profession of IT beyond computational thinking. Communications of the ACM, 52, 28-30. https://doi.org/10.1145/ 1610252.1610265

Denning, P. J. (2017). Remaining trouble spots with computational thinking. Communications of the ACM, 60(6), 33-39 https://doi.org/10.1145/ 2998438

Dewey, J. (1996). Art as experience. TarcherPerigee.

Doleck, T., Bazelais, P., Lemay, D. J., Saxena, A., \& Basnet, R. B. (2017). Algorithmic thinking, 
cooperativity, creativity, critical thinking, and problem solving: Exploring the relationship between computational thinking skills and academic performance. Journal of Computers in Education, 4(4), 355-369. https://doi.org/10.1007/ s40692-017-0090-9

Dolgopolovas, V., \& Dagienė, V. (2021). Computational thinking: Enhancing STEAM and engineering education, from theory to practice. Computer Applications in Engineering Education, 29(1), 5-11. https://doi.org/10.1002/cae.22382

Ergün, A., \& Kuilekci, E. (2019). The effect of problem based STEM education on the perception of 5th grade students of engineering, engineers and technology. Pedagogical Research, 4(3), em0037. https://doi.org/10.29333/pr/5842

Frappier, M., Meynell, L., \& Brown, J. R. (Eds.). (2013). Special Issue: Visual representations and reasoning. The Knowledge Engineering Review, 28(3), f1-f2. https:/ / doi.org/10.1017/S0269888913000362

Gal-Ezer, J., \& Zur, E. (2004). The efficiency of algorithms-misconceptions. Computers $\mathcal{E}$ Education, 42(3), 215-226. https:/ / doi.org/10.1016/ j.compedu.2003.07.004

Garner, G., Reed, P., \& Keller, K. (2016). Climate risk management requires explicit representation of societal trade-offs. Climatic Change, 134(4), 713-723. https:// doi.org/10.1007/s10584-016-1607-3

Gatan, P. R. G., Yangco, R. T., \& Monterola, S. L. C. (2021). Relationships among environmental literacy, locus of control, and future orientation of STEM students in the Philippines. Interdisciplinary Journal of Environmental and Science Education, 17(4), e2250. https://doi.org/10.21601/ijese/10984

Gibbons, P., McMahon, A., \& Wiegers, J. (2003). Handson current electricity: A professional development course. Journal of Elementary Science Education, 15(2), 1-11. https:/ / doi.org/10.1007/BF03173839

Groff, J., Howells, C., \& Cranmer, S. (2010). The impact of console games in the classroom: Evidence from schools in Scotland. Futurelab.

Gunawan, S., \& Shieh, C. J. (2020). Effects of the implementation of stem curriculum integration model to living technology teaching on business school students' learning effectiveness. Contemporary Educational Technology, 12(2), ep279. https:// doi.org/10.30935/cedtech/8583

Hammer, S. (2014). Science, art, and aesthetics: An interdisciplinary approach to abstract reasoning. European Scientific Journal, ESJ, 10(10), 72-76.

Hekkert, P. \& Leder, H. (2007). Product aesthetics. In H. N. J. Schifferstein, \& P. Hekkert (Eds.), Product experience (pp. 259-285). Elsevier. https:// doi.org/ 10.1016/B978-008045089-6.50013-7
Henderson, P. B., Cortina, T. J., \& Wing, J. M. (2007). Computational thinking. ACM SIGCSE Bulletin, 39(1), 195-196. https://doi.org/10.1145/1227504. 1227378

Henriksen, D. (2014). Full STEAM ahead: Creativity in excellent STEM teaching practices. The STEAM Journal, 1(2), 15. https://doi.org/10.5642/steam. 20140102.15

Hetland, L. (2013). Studio thinking 2: The real benefits of visual arts education. Teachers College Press. https:/ / eric.ed.gov/?id=ED497825

Hsu, T.-C., Chang, S.-C., \& Hung, Y.-T. (2018). How to learn and how to teach computational thinking: Suggestions based on a review of the literature. Computers \& Education, 126, 296-310. https:// doi.org/10.1016/j.compedu.2018.07.004

Iglesias, M. J., Müller, J., Ruiz-Mallen, I., Kim, E., Cripps, E., Heras, M., Martins, S. F., van Laar, M., Tramonti, M., Valenzuela-Zapata, A., Gras-Velázquez, À., Da Silva, A. A., Alexopoulos, A., Baldursson, R., Bes, M., Benameur, Z., Bogner, F. X., Cala, V., Ceuleers, E., ... Vizzini, C. (2018). Gender and innovation in STE(A)M education. Scientix Observatory. http:/ / www.scientix.eu/documents/10137/75267 7/Scientix-SPNE12-Gender-Innovation-STEAM_ Final.pdf/e907b19e-0863-4502-a396-9ad6a5184be0

ISTE. (2015). CT leadership toolkit.

Jolly, A. (2014). STEM vs. STEAM: Do the arts belong? EdWeek.org. Education Week: Teacher.

Kang, M., Jang, K., \& Kim, S. (2013). Development of 3D actuator-based learning simulators for robotics STEAM education. International Journal of Robots, Education and Art, 3(1), 22-32. https:/ / doi.org/10.4156/ijrea.vol3.issue1.3

Kang, N. H. (2019). A review of the effect of integrated STEM or STEAM (science, technology, engineering, arts, and mathematics) education in South Korea. Asia-Pacific Science Education, 5(1), 1-22. https://doi.org/10.1186/s41029-019-0034-y

Kelley, T. R., \& Knowles, J. G. (2016). A conceptual framework for integrated STEM education. International Journal of STEM Education, 3(1), 11. https:// doi.org/10.1186/s40594-016-0046-Z

Korkmaz, Ö., Çakir, R., \& Özden, M. Y. (2017). A validity and reliability study of the Computational Thinking Scales (CTS). Computers in Human Behavior, 72, 558-569. https://doi.org/10.1016/ j.chb.2017.01.005

Land, M. H. (2013). Full STEAM ahead: The benefits of integrating the arts into STEM. Procedia Computer Science, 20, 547-552. https://doi.org/10.1016/ j.procs.2013.09.317

Li, Y. (2018). Journal for STEM education research Promoting the development of interdisciplinary research in STEM education. Journal for STEM 
Education Research, 1(1-2), 1-6. https://doi.org/ 10.1007/s41979-018-0009-Z

Li, Y., Schoenfeld, A. H., Graesser, A. C., Benson, L. C., English, L. D., \& Duschl, R. A. (2020). On Computational Thinking and STEM Education. Journal for STEM Education Research, 3, 147-166. https:/ / doi.org/10.1007/s41979-020-00044-w

Liao, C. (2016). Creating a STEAM map: A content analysis of virtual art practices in STEAM education. Art Education, 69(6), 22-29. https:/ / doi.org/10.1080/00043125.2016.1224873

Liliawati, W., Rusnayati, H., \& Aristantia, G. (2018). Implementation of STEAM education to improve mastery concept. In IOP Conference Series: Materials Science and Engineering (Vol. 288, No. 1, p. 012148). IOP Publishing. https://doi.org/10.1088/1757899X/288/1/012148

Lin, C., Huang, J., \& Lin, R. (2021). From STEAM to CHEER: A case study of design education development in Taiwan. Education Sciences, 11(4), 171. https:/ / doi.org/10.3390/educsci11040171

McAllister, J. W. (1996). Beauty and revolution in science. Cornell University Press.

McGrath, M. B., \& Brown, J. R. (2005). Visual learning for science and engineering. IEEE Computer Graphics and Applications, 25(5), 56-63. https:// doi.org/10.1109/MCG.2005.117

Meinck, S., \& Brese, F. (2019). Trends in gender gaps: using 20 years of evidence from TIMSS. Large-Scale Assessments in Education, 7, 8. https:/ / doi.org/10.1186/s40536-019-0076-3

Metz, S. S. (2007). Attracting the engineering of 2020 today. In R. Burke, M. Mattis, \& E. Elgar (Eds.), Women and minorities in science, technologies, engineering and mathematics: Upping the numbers (pp. 184-209). Edward Elgar Publishing.

Michaelson, G. (2018). Microworlds, objects first, computational thinking and programming. In M.S. Khine (Ed.), Computational thinking in the STEM disciplines (pp. 31-48). Springer. https://doi.org/10.1007/978-3-319-93566-9_3

Moore, T. J., Stohlmann, M. S., Wang, H. H., Tank, K. M., Glancy, A. W., \& Roehrig, G. H. (2014). Implementation and integration of engineering in $\mathrm{K}-12$ STEM education. In Engineering in pre-college settings: Synthesizing research, policy, and practices. Purdue University Press. https:/ / doi.org/10.2307/ j.ctt6wq7bh.7

National Research Council (2012a). A framework for K12 science education: Practices, crosscutting concepts, and core ideas. National Academies Press.

National Research Council (2012b). Discipline-based education research: understanding andimproving learning in undergraduate science and engineering. National Academies Press.
OECD (2018). PISA, PISA 2015 results in focus. http://www.oecd.org/pisa/test/

Oner, A. T., Nite, S. B., Capraro, R. M., \& Capraro, M. M. (2016). From STEM to STEAM: Students' beliefs about the use of their creativity. The STEAM Journal, 2(2), 6. https:// doi.org/10.5642/steam.20160202.06

Papanikolaou, K. (2010). Introducing robotics to teachers and schools: Experiences from the terecop project. Constructivism: Paris. http://hermes.di.uoa.gr/ frangou/papers/eurologo\%202010.pdf

Park, H., Byun, S. Y., Sim, J., Han, H. S., \& Baek, Y. S. (2016). Teachers' perceptions and practices of STEAM education in South Korea. Eurasia Journal of Mathematics, Science and Technology Education, 12(7), 1739-1753.

https:/ / doi.org/10.12973/eurasia.2016.1531a

Park, S. Y., Song, K. S., \& Kim, S. H. (2015). Cognitive load changes in pre-service teachers with computational thinking education. International Journal of Software Engineering and Its Applications, 9(10), 169-178. https:// doi.org/10.14257/ijseia. 2015.9.10.17

Piro, J. (2010). Going from STEM to STEAM: The arts have a role in America's future, too. [Web log post]. http:/ / performingartsworkshop.wordpress.com/ 2010/03/15/education-week-article-goingfromstem-to-steam

Psycharis, S. (2018). STEAM in education: A literature review on the role of computational thinking, engineering epistemology and computational science. Computational STEAM pedagogy (CSP). Scientific Culture, 4(2), 51-72.

Qin, H. (2009). Teaching computational thinking through bioinformatics to biology students. ACM SIGCSE Bulletin, 41(1), 188-191. https:/ / doi.org/10.1145/1539024.1508932

Quigley, C. F., \& Herro, D. (2016). Finding the joy in the unknown: Implementation of STEAM teaching practices in middle school science and math classrooms. Journal of Science Education and Technology, 25(3), 410-426. https:/ / doi.org/10.1007 / s10956-016-9602-z

Root-Bernstein, R. (1997). The sciences and arts share a common creative aesthetic. In A. I. Tauber (Ed.), The elusive synthesis: Aesthetics and science (pp. 49-82). Kluwer Academic Publishers. https://doi.org/ 10.1007/978-94-009-1786-6_3

Ruiz-Mallén, I., Muller J., Kim. E., (2017). How to address gender stereotypes in science education through innovation based on arts-based approaches? https://www.slideshare.net/Scientix/spne12workshop-how-to-address-gender-stereotypes-inscience-education-through-innovation-based-onartsbased-approaches/ 
Sahin, A., Gulacar, O., \& Stuessy, C. (2014). High school students' perceptions of the effects of International Science Olympiad on their STEM career aspirations and twenty-first century skill development. Research Science Education, 45, 785-805. https:/ / doi.org/10.1007/s11165-014-9439-5

Sawilowsky, S. S. (2009). New effect size rules of thumb. Journal of Modern Applied Statistical Methods, 8(2), 597-599.

https:/ / doi.org/10.22237/jmasm/1257035100

Segarra, V. A., Natalizio, B., Falkenberg, C. V., Pulford, S., \& Holmes, R. M. (2018). STEAM: Using the arts to train well-rounded and creative scientists. Journal of Microbiology E Biology Education, 19(1), 17. https:/ / doi.org/10.1128/jmbe.v19i1.1360

Shute, V. J., Sun, C., \& Asbell-Clarke, J. (2017). Demystifying computational thinking. Educational Research Review, 22, 142-158. https://doi.org/ 10.1016/j.edurev.2017.09.003

Spyropoulou, C., Wallace, M., Vassilakis, C., \& Poulopoulos, V. (2020). Examining the use of STEAM Education in Preschool Education. European Journal of Engineering and Technology Research.

https:/ / doi.org/10.24018/ejers.2020.0.CIE.2309

Süzen, H. N. (2020). Art and Aesthetics in Higher Education. Online Submission, 7(6), 335-350. https:/ / doi.org/10.46827/ ejes.v7i6.3156

Tan, W. L., Samsudin, M. A., Ismail, M. E., \& Ahmad, N. J. (2020). Gender differences in students' achievements in learning concepts of electricity via steam integrated approach utilizing Scratch. Problems of Education in the 21st Century, 78(3), 423. https://doi.org/10.33225/pec/20.78.423

Tunc, C., \& Bagceci, B. (2021). Teachers' views of the implementation of STEM approach in secondary schools and the effects on students. Pedagogical
Research, 6(1), em0085. https://doi.org/10.29333/ pr/9295

UNESCO. (2017). Cracking the code: girls' and women's education in science, technology, engineering and mathematics (STEM).

United Nations. (2015). Resolution adopted by the general assembly on 25 September 2015. Transforming our world: the 2030 Agenda for Sustainable Development. Sustainable Development Goals Knowledge Platform.

van Maanen, H. (2009). How to study art worlds. On the societal functioning of aesthetic values. Amsterdam University Press.

Weintrop, D., Beheshti, E., Horn, M., Orton, K., Jona, K., \& Trouille, L. (2016). Defining computational thinking for mathematics and science classrooms. Journal of Science Education and Technology, 25, 127147. https:/ / doi.org/10.1007/s10956-015-9581-5

Wickman, P.-O. (2006). Aesthetic experience in science education: Learning and meaning-making as situated talk and action. Lawrence Erlbaum.

Wing, J. (2011). Research notebook: Computational thinkingWhat and Why?. http:/ / www.cs.cmu.edu/ Comp Think/resources/TheLinkWing.pdf

Wing, J. M. (2006). Computational thinking. Communication of the ACM, 49(3), 33-35. https:// doi.org/10.1145/1118178.1118215

Yakman, G. (2008). STEAM education: An overview of creating a model of integrative education. In Pupils' Attitudes Towards Technology (PATT-19) Conference: Research on Technology, Innovation, Design $\mathcal{E}$ Engineering Teaching, Salt Lake City, Utah, USA.

Yakman, G. (2010). What is the point of STE@M? - A brief overview. http://www.academia.edu/8113832/ What_is_the_Point_of_STEAM_A_Brief_Overview _of_STEAM_Education

\section{http://www.ejmste.com}

